УДК 581.9(470.316)

DOI 10.18413/2658-3453-2019-1-4-209-217

\title{
ЗАПАСЫ СЫРЬЯ NUPHAR LUTEA (L.) SM. В ВЕРХОВЬЕ МАЛОЙ РЕКИ ИЛЬД (ЯРОСЛАВСКАЯ ОБЛАСТЬ)
}

\author{
STOCKS OF NUPHAR LUTEA (L.) SM. IN SMALL RIVER ILD \\ (YAROSLAVL REGION, RUSSIA)
}

\author{
А.М. Чернова, Д.А. Филиппов \\ A.M. Chernova, D.A. Philippov \\ Институт биологии внутренних вод им. И.Д. Папанина РАН, \\ Россия 152742, Ярославская область, пос. Борок \\ Papanin Institute for Biology of Inland Waters Russian Academy of Sciences, \\ Borok, Yaroslavl Region, 152742, Russia \\ E-mail: nuphar@mail.ru
}

\begin{abstract}
Аннотация
Изучен растительный покров верховья малой реки Ильд (Ярославская область) и произведена оценка запасов растительного сырья кубышки жёлтой (Nuphar lutea) - ценного лекарственного растения. Исследования проводили маршрутно-ключевым методом в 2013 г. в период максимального развития гидрофитов и их массового цветения, на участке реки протяжённостью более 10 км. Было зафиксировано 69 видов сосудистых растений из 55 родов 35 семейств. В верховьях р. Ильд имеет сплошной многоярусный характер зарастания, и его общая площадь составляет более $80 \%$. Основные заросли кубышки в реке сосредоточены именно в верховьях. Проективное покрытие в кубышковых ценозах чаще всего составляет 50-80\%. Запасы Nuphar lutea на обследованном участке р. Ильд составляют более 25 га, что в пересчёте на воздушносухое вещество составляет не менее 140625 кг. Подсчитан запас некоторых наиболее значимых летучих низкомолекулярных органических соединений в составе кубышки: фитол - не менее 1.69 кг, маноол - 13.5 кг, фурфурол - 0.45 кг. Малую р. Ильд можно рекомендовать для сбора растительного сырья.
\end{abstract}

\begin{abstract}
The yellow water-lily - Nuphar lutea (L.) Sm. (Nymphaeaceae Salisb.) - is a true perennial hydrophyte with a strong rootstock and leaves floating on the water. The yellow water-lily is an ornamental, edible, and medicinal plant which is widely used in conventional and alternative medicine. This is not a culture plant; therefore, the only source of the raw material for medicinal use is wild-growing species. Typical habitats for yellow water-lilies are small rivers. In the present study, we estimated the resources of the yellow water-lily in the small Ild River (Yaroslavl Region, Russia) as well as investigated the vegetation cover of this river. Our field research was conducted using the combined route and key-site method during the peak growths of hydrophytes and period of their maximum flowering (July to August 2013). The site over $10 \mathrm{~km}$ long was covered. Field works included the preparation of floristic and geobotanical descriptions, recording of abiotic growing conditions of macrophytes, and photographic survey. Areas covered with yellow water-lily were estimated visually in square meters, taking into account its projective cover in plant communities. In the upper reach of the studied river, hydrophytes and helophytes form the basis of plant communities. Of all hydrophytes, $N$. lutea plays the most important role in the overgrowing. In the upper reaches, this species forms monodominant or almost-monodominant communities occupying not only the edges of the riverbed, but the whole riverbed. In the upper reaches, the Ild River has a continuous multi-tiered character of overgrowing and its total area is more than $80 \%$. The projective cover of yellow water-lily communities is most often $50 \%$ to $80 \%$. We estimate that the resources of $N$. lutea in the investigated region of the Ild River is more than 25 hectares, or at least $140625 \mathrm{~kg}$ of air-dry substance. Within the investigated site of $10 \mathrm{~km}$ long, we observed 69 species of 55 genera of 35 families of vascular plants. The taxonomic composition of the flora of the upper reach of the Ild River is similar to that of the other water streams of the south-taiga subarea of the European part of Russia. The flora
\end{abstract}


includes adventitious plant such as Elodea canadensis and Heracleum sosnowskyi which indicate the anthropogenic exploitation of this territory. We can recommend small rivers for collecting yellow waterlily raw material. The work was carried out within the government order of the Ministry of Education and Science of the Russian Federation (No. AAAA-A18-118012690099-2).

Ключевые слова: растительный покров, растительные ресурсы, малая река, фитоценоз, кубышка жёлтая, летучие низкомолекулярные органические соединения, фитол, маноол, фурфурол

Keywords: vegetation cover, vegetation resources, small river, phytocoenosis, yellow water lilly, lowmolecular volatile organic compounds, phytol, manol, furfural

\section{Введение}

Кубышка жёлтая Nuphar lutea (L.) Sm. (Nymphaeaceae Salisb.) - истинно водное многолетнее растение с мощным корневищем и плавающими на воде листьями. Вид имеет европейско-западноазиатский умеренно тёплый ареал и предпочитает произрастать в заливах и на мелководьях водохранилищ и озёр, в стоячих и слабопроточных участках рек [Атлас..., 1980; Цвелёв, 2000]. Кубышка жёлтая - популярный объект для исследователей. В последние годы получены и дополнены сведения о биологических [Klimenko, 2012; Marrottea et al., 2012; Чернова, 2013, 2014 и др.; Kordyum, Klimenko, 2013; Chernova, 2015, 2019; Бобров, 2017; Didukh et al., 2017] и экологических [Mazej, Germ, 2009; Nurminen, Horppila, 2009] особенностях вида, а также о консортивных связях с другими организмами [Воронин, Черняковская, 2010; Ивичева, Филиппов, 2017; Czeczuga et al., 2018; Ivanova et al., 2018]. Кубышка является лекарственным растением, широко использующимся в народной и традиционной медицине. В различных частях $N$. lutea содержатся такие химически активные вещества как стероиды, фенолкарбоновые кислоты, алкалоиды, высшие жирные [Elakovich, Yang 1996; Беленовская, Медведева, 2008; Курашов и др., 2013; Fedotcheva et al., 2017; Шейченко и др., 2019], за счёт которых вид обладает разнообразными лечебными свойствами [Гаммерман, Гром, 1976; Махлаюк, 1992; Гончарова, 1998]. Анализруются перспективы использования экстрактов кубышки жёлтой как противовоспалительного средства [Ozer et al., 2015] и средства против лейшманиоза [El-On et al., 2009], в качестве ингибитора опухолевых заболеваний [Yildirim et al., 2013]. Важно отметить, что именно дикорастущая кубышка является единственным источником лекарственного сырья, так как данный вид не введён в культуру [Кузнецова, 1987].

В настоящей работе мы ставили перед собой целью изучить растительный покров малой реки (на примере р. Ильд) для оценки запасов растительного сырья кубышки жёлтой.

\section{Материал и методы исследования}

Исследования проводили на р. Ильд (Некоузский район, Ярославская область), бассейн которой находится в верхнем течении р. Волга и относится к Костромскому

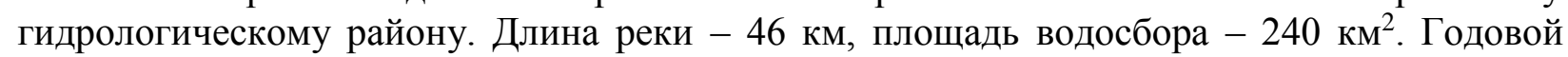
сток неравномерен: весенний - $74 \%$, летне-осенний - $20 \%$, зимний - $6 \%$. Среднемноголетний расход - $1.26 \mathrm{~m}^{3} /$ сек. Река характеризуется смешанным питанием (реализуется за счёт таяния снегов, летних и осенних дождей и грунтовых вод). Максимальные значения минерализации составляют 1190 мг/л, минимальные (регистрируемые при увеличении количества осадков и зарегулировании стока) 450 мг/л. Вода имеет слабощелочную реакцию. Максимальные величины БПК 5 (биохимического потребления кислорода за 5 суток) фиксируются в верхнем течении и характеризуют воды верховья как «грязные» или «очень грязные», а в нижнем течении воды относятся к классу «чистые» [Гидроэкология..., 2015].

Река неоднородна в своём течении. В её верховье воды преимущественно медленно текучие, почти стоячие с многочисленными бобровыми запрудами и прудами 
антропогенного происхождения. В средней части водотока течение ускоряется, местами образуются перекаты. Выделяется также зона подпора Рыбинским водохранилищем.

Полевые исследования проводили маршрутно-ключевым методом в июле-августе 2013 г., что совпадает с периодом максимального развития гидрофитов и их массового цветения. Проводился пеший маршрут вдоль русла реки от д. Федосово (5758'31" с. ш. $38^{\circ} 12^{\prime} 12^{\prime \prime}$ в. д.) до д. Сусловка $\left(57^{\circ} 55^{\prime} 02^{\prime \prime}\right.$ с. ш. $38^{\circ} 03^{\prime} 33^{\prime \prime}$ в. д.). Пройден участок более 10 км. Работы велись по описанной ранее методике [Лобуничева и др., 2013]. В частности выполнялись флористические и геоботанические описания, фиксировались абиотические условия произрастания макрофитов (глубина, течение, грунт), велась фотосъёмка. Площади, занимаемые кубышкой жёлтой, оценивали визуально в квадратных метрах, учитывали её проективное покрытие в растительных сообществах. Гербарный материал хранится в лаборатории высшей водной растительности ИБВВ РАН. Номенклатура таксонов приводится по сводке Н.Н. Цвелёва [2000].

\section{Результаты и их обсуждение}

Состав флоры. На изученном участке реки Ильд было зафиксировано 69 видов сосудистых растений из 55 родов 35 семейств. Ниже приведён список видов, сгруппированных по семействам, расположенным в алфавитном порядке (вначале перечислены споровые, затем - семенные растения).

Сем. Equisetaceae Rich. ex DC.: Equisetum fluviatile L.; E. pratense Ehrh.

Cем. Alismataceae Vent.: Alisma plantago-aquatica L.; Sagittaria saggitifolia L.

Сем. Apiaceae Lindl.: Aegopodium podagraria L.; Heracleum sosnowskyi Manden.; Oenanthe aquatica (L.) Poir.; Sium latifolium L.

Сем. Asteraceae Dumort.: Bidens tripartita L.; Gnaphalium uliginosum L.

Сем. Betulaceae S.F. Gray: Alnus incana (L.) Moench

Cем. Boraginaceae Juss.: Myosotis palustris (L.) L.

Сем. Brassicaceae Burnett: Cardamine dentata Schult.; Rorippa palustris (L.) Bess.

Cем. Butomaceae Rich.: Butomus umbellatus L.

Сем. Cannabaceae Endl.: Humulus lupulus L.

Сем. Caryophyllaceae Juss.: Stellaria sp.

Сем. Chenopodiaceae Vent.: Chenopodium sp.

Сем. Cyperaceae Juss.: Carex acuta L.; C. pseudocyperus L.; C. vesicaria L.; C. vulpina L.; Eleocharis palustris (L.) Roem. et Schult. s.1.; Eleocharis sp.; Schoenoplectus lacustris (L.) Palla

Cем. Fabaceae Lindl.: Lathyrus pratensis L.; Vicia cracca L.

Сем. Grossulariaceae DC.: Ribes nigrum L.

Cем. Hydrocharitaceae Juss.: Elodea canadensis Michx.

Cем. Juncaceae Juss.: Juncus bufonius L.

Cем. Lamiaceae Lindl.: Lycopus europaeus L.; Mentha arvensis L.; Scutellaria galericulata $\mathrm{L}$.

Cем. Lemnaceae S.F. Grey: Lemna minor L.; Spirodela polyrhiza (L.) Schleid.; Staurogeton trisulcus (L.) Schur

Сем. Lentibulariaceae Rich.: Utricularia vulgaris L.

Сем. Lythraceae J.St.-Hil.: Lythrum salicaria L.

Cем. Nymphaeaceae Salisb.: Nuphar lutea (L.) Sm.

Сем. Onagraceae Juss.: Epilobium montanum L.; E. palustre L.

Cем. Pediculariaceae Juss.: Melampyrum nemorosum L.

Cем. Poaceae Barnhart: Agrostis stolonifera L.; Glyceria fluitans (L.) R. Br.; Phalaroides arundinacea (L.) Rausch.; Phragmites australis (Cav.) Trin. ex Steud.

Cем. Polygonaceae Juss.: Persicaria amphibia (L.) S.F. Gray; Persicaria sp.; Rumex aquaticus L.; R. hydrolapathum Huds. 
Ceм. Potamogetonaceae Dumort.: Potamogeton natans L.

Cем. Primulaceae Juss.: Lysimachia nummularia L.; L. vulgaris L.; Naumburgia thyrsiflora (L.) Reichb.

Cем. Ranunculaceae Juss.: Caltha palustris L.; Ranunculus repens L.; Thalictrum sp.

Сем. Rosaceae Juss.: Filipendula denudata (J. et C. Presl) Fritsch; Padus avium Mill.

Cем. Rubiaceae Juss.: Galium palustre L.

Cем. Salicaceae Mirb.: Salix cinerea L.; S. fragilis L.; S. myrsinifolia Salisb.; S. pentandra L.

Cем. Solanaceae Juss.: Solanum dulcamara L.

Сем. Sparganiaceae Rudolphi: Sparganium emersum Rehm.; S. microcarpum (Neum.) Raunk.

Cем. Typhaceae Juss.: Typha latifolia L.

Сем. Urticaceae Juss.: Urtica dioica L.

Таксономический состав флоры верховьев р. Ильд схож не только с флорой нижележащих участков данной реки, находящихся в зоне подпора водохранилища [Крылова, 2015], но и с таковой других водотоков подзоны южной тайги Европейской России [Лисицына и др., 2009; Krylova, 2010; Ivicheva et al., 2018 и др.]. Присутствие во флоре адвентивных растений (элодея канадская, борщевик Сосновского) указывает на антропогенную освоенность данной территории, а наличие древесно-кустарниковых и мезофитных растений обусловлено как небольшими размерами малой реки в её верховьях, так и особенностями растительного покрова примыкающих к водотоку биотопов.

Зарастание реки. Основу ценозов верховьев анализируемой реки составляют гидрофиты и гелофиты. Наибольшую роль играют N. lutea, E. fluviatile, виды семейства Lemnaceae. Перечисленные виды макрофитов формируют хвощёвые, хвощёво-рясковые, хвощёво-кубышковые, кубышково-рясковые, рясковые, кубышковые сообщества и встречаются преимущественно в пределах всего русла (реже только по его краям). На некоторых участках могут также доминировать и содоминировать E. canadensis, P. natans, S. latifolia, T. latifolia. По урезу воды и на прилегающих участках берегов, как правило, развиваются ценозы двукисточника, осоки острой.

Характер зарастания [по: Синкявичене, 1992] сплошной многоярусный: макрофиты занимают значительную часть русла реки, при этом в самом русле формируются как сообщества гидрофитов, так и гелофитов. Данный тип характерен для рек в хорошо освоенных (с сельскохозяйственной точки зрения) районах и реках с медленным течением и небольшими глубинами. По нашим оценкам зарастание верхних участков р. Ильд составляет более $80 \%$.

Растительные ресурсы. Кубышка жёлтая встречается на всём протяжении реки, однако основные заросли сосредоточены в верховьях. Здесь практически отсутствует течение, глубина воды составляет 0.5-1.5 м, грунт илистый (до 20 см толщины). Кубышка жёлтая образует обширные монодоминантные заросли, занимая иногда всё русло.

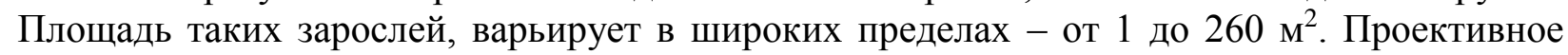
покрытие кубышковых ценозов чаще всего составляет 50-80\%. По нашим оценкам запасы $N$. lutea на пройденном участке р. Ильд составляют более 25 га. По разным данным [Чернова, 2013; Шарапов и др., 2013; Chernova, 2015] в период массового развития кубышки $1 \mathrm{~m}^{2}$ её зарослей даёт от 2 до 5.5 кг сырой надземной биомассы. В пересчёте на воздушно-сухую массу это в среднем 0.562 кг/м². То есть ресурс кубышки в верховье р. Ильд составляет не менее 140625 кг воздушно-сухого вещества.

Ранее нами было показано, что в листьях кубышки жёлтой содержится более 130 летучих низкомолекулярных органических соединений (ЛНОС) [Курашов и др., 2013]. У $N$. lutea из р. Ильд ЛНОС составляют не менее 0.228 мг/г сухой массы. Наиболее значимый вклад в состав ЛНОС кубышки вносят жирные кислоты (тетрадекановая, пентадекановая, гексадекановая, линолевая и линоленовая), фталаты (диизобутилфталат и 
дибутилфталат), а также дитерпеновый спирт фитол [Kurashov et al., 2014]. Последний обладает выраженной антибактериальной активностью, и его запасы в верховьях реки могут составлять не менее 1.68 кг.

Некоторые вещества, обнаруженные в составе ЛНОС кубышки, заслуживают особого внимания. Например, среди терпеновых соединений преобладает маноол (содержание сухого вещества в листовых пластинках - $0.0024 \mathrm{мг} / \Gamma$, в черешках 0.0972 мг/Г). Природный маноол интересен как ценный ресурс для отраслей медицины, фармацевтики и парфюмерии. N. lutea по способности к синтезу маноола может быть отнесена к группе растений-концентраторов с умеренным содержанием данного вещества [Курашов и др., 2013; Kurashov et al., 2014]. В первом пересчёте определённых нами ресурсов кубышки потенциально маноола на анализируемом участке р. Ильд составляет более чем 13 кг.

Среди метаболитов $N$. lutea в достаточно большой концентрации (как в листовых пластинках, так и в черешках) содержится фурфурол - вещество, широко используемого в химической и в химико-фармацевтической промышленности как исходное сырье для синтеза различных соединений (например, антимикробных препаратов группы нитрофуранов, таких как, фурацилин) [Kurashov et al., 2014]. По нашим расчётам запас фурфурола в верхнем течение реки не менее 0.45 кг.

В целом, наши исследования показывают, что малая р. Ильд имеет характерный для равнинной части южнотаёжной подзоны Европейской территории России облик, а массовые/доминирующие виды макрофитов обладают значительным потенциалом с точки зрения запасов и доступности возобновляемого растительного сырья.

\section{Благодарности}

Работа выполнена в рамках государственного задания Министерства науки и высшего образования РФ (АААA-А18-118012690099-2).

\section{Список литературы}

1. Атлас ареалов и ресурсов лекарственных растений СССР. 1980. М., Главное управление геодезии и картографии при Совете Министров СССР, 340 с.

2. Беленовская Л.М., Медведева Л.И. 2008. Сем. 2. Nymphaeaceae Salisb. - Кувшинковые. $B$ кн.: Растительные ресурсы России: Дикорастущие цветковые растения, их компонентный состав и биологическая активность. Т. 1. Семейства Magnoliaceae - Junglandaceae, Ulmaceae, Moraceae, Cannabaceae, Urticaceae. СПб., М., Товарищество научных изданий КМК: 18-20.

3. Бобров Ю.А. 2017. Жизненные формы водных трав Северо-востока Европейской России. Arctic Environmental Research, 17 (2): 104-112. DOI: 10.17238/issn2541-8416.2017.17.2.104.

4. Воронин Л.В., Черняковская Т.Ф. 2010. Сукцессии комплексов микроорганизмов на разлагающихся листьях Nuphar lutea в малой реке Латке. Ярославский педагогический вестник, 3 (1): 87-91.

5. Гаммерман А.Ф., Гром И.И. 1976. Дикорастущие лекарственные растения СССР. М., Медицина, 288 с.

6. Гидроэкология устьевых областей притоков равнинного водохранилища. 2015. А.В. Крылов (ред.). Ярославль, Филигрань, 466 с.

7. Гончарова Т.А. 1998. Энциклопедия лекарственных растений. Лечение травами. Т. 1. М., Издательский Дом МСП, 560 с.

8. Ивичева К.Н., Филиппов Д.А. 2017. Водные макробеспозвоночные верховых болот центральной части Вологодской области. Труды Карельского научного центра РАН, (9): 30-45. DOI: $10.17076 /$ eco472.

9. Кузнецова М.А. 1987. Лекарственное растительное сырьё и препараты. М., Высшая школа, 190 с.

10. Курашов Е.А., Крылова Ю.В., Чернова А.М., Митрукова Г.Г. 2013. Компонентный состав летучих низкомолекулярных органических веществ Nuphar lutea (Nymphaeaceae) в начале вегетационного сезона. Вода: химия и экология, (5): 67-80. 
11. Лисицына Л.И., Папченков В.Г., Артёменко В.И. 2009. Флора водоёмов волжского бассейна. Определитель сосудистых растений. М., Товарищество научных изданий КМК, 219 с.

12. Лобуничева Е.В., Борисов М.Я., Филоненко И.В., Филиппов Д.А. 2013. Оценка экологического состояния малых водоёмов. Вологда, ГосНИОРХ, 218 с.

13. Махлаюк В.П. 1992. Лекарственные растения в народной медицине. М., Нива России, 477 с.

14. Синкявичене 3.В. 1992. Характеристика растительности средних и малых рек Литвы. Автореф. дис. ... канд. биол. наук. Вильнюс, 28 с.

15. Цвелёв Н.Н. 2000. Определитель сосудистых растений Северо-Западной России (Ленинградская, Псковская и Новгородская области). СПб., Изд-во СПХФА, 781 с.

16. Чернова А.М. 2013. Сезонная динамика продуктивности кубышки жёлтой (Nuphar lutea, Nymphaeaceae) в условиях малых рек Верхнего Поволжья. Автореф. дис. ... канд. биол. наук. Борок, $23 \mathrm{c}$.

17. Чернова А.М. 2014. Зависимость массы корневищ Nuphar lutea (Nymphaeaceae) от их морфометрических показателей. Растительные ресурсы, 50 (1): 17-24.

18. Шарапов А.В., Чемерис Е.В., Бобров А.А. 2013 Запасы надземной фитомассы речных макрофитов Верхнего Поволжья и её сезонная динамика. Растительные ресурсы, 49 (1): 48-56.

19. Шейченко В.И., Толкачёв О.Н., Осипов В.И., Шейченко О.П., Ануфриева В.В., Тимошина В.А., Фатеева Т.В., Бортникова В.В., Быков В.А. 2019. Состав и биологическая активность фуран охинолизидиновых алкалоидов из корневищ кубышки жёлтой (Nuphar lutea L. Smith). Химико-фармацевтический журнал, 53 (6): 42-47. DOI: 10.30906/0023-1134-2019-53-6-42-47.

20. Chernova A.M. 2015. Seasonal dynamics of yellow water lily Nuphar lutea (L.) Smith (Nymphaeaceae) in the small Ild river (Yaroslavl Oblast). Inland Water Biology, 8 (2): 157-165. DOI: $10.1134 /$ S1995082915020042.

21. Chernova A.M. 2019. Non-destructive estimation of the leaf area in Nuphar lutea L. (Nymphaeaceae). Phytomorphology, 13: 20-25. DOI: 10.5281/zenodo.190105.

22. Czeczuga B., Czeczuga-Semeniuk E., Semeniuk-Grell A., Godlewska A., Muszyńska E. 2018. Influence of different parts of yellow and white water lilies (Nymphaeaceae) on aquatic mycotal species diversity. Nova Hedwigia, 107 (3-4): 367-384. DOI: 10.1127/nova_hedwigia/2018/0483.

23. Didukh M.Ya., Didukh G.Ya., Mazur T.P., Nuzhyna N.V. 2017. Biomorphological and anatomic researches of Nymphaea alba, Nuphar lutea and Nuphar pumila in outdoor and indoor ponds in the A.V. Fomin botanical garden. Hydrobiological Journal, 53 (3): 52-59. DOI: $10.1615 /$ HydrobJ.v53.i3.50.

24. El-On J., Ozer J., Gopas J., Sneir R., Golan-Goldhirsh A. 2009. Nuphar lutea: In vitro antileishmanial activity against Leishmania major promastigotes and amastigotes. Phytomedicine, 16 (8): 788-792. DOI: 10.1016/j.phymed.2009.01.011.

25. Elakovich S.D., Yang J. 1996. Structures and allelopathic effects of Nuphar alkaloids: Nupharolutine and 6,6'-dihydroxythiobinupharidine. Journal of Chemical Ecology, 22 (12): 2209-2219. DOI: $10.1007 / \mathrm{BF} 02029541$.

26. Fedotcheva T.A., Shimanovskii N.L., Sheichenko O.P., Anufrieva V.V., Sheichenko V.I., Fedotcheva N.I. 2017. Preparation of Nuflein - an alkaloid from the yellow waterlilly Nuphar lutea - and its cytotoxic action on cultures of normal and tumorous human cells. Pharmaceutical Chemistry Journal, 51 (7): 590-595. DOI: 10.1007/s11094-017-1658-4.

27. Ivanova A.A., Philippov D.A., Kulichevskaya I.S., Dedysh S.N. 2018. Distinct diversity patterns of Planctomycetes associated with the freshwater macrophyte Nuphar lutea (L.) Smith. Antonie van Leeuwenhoek, 111 (6): 811-823. DOI: 10.1007/s10482-017-0986-4.

28. Ivicheva K.N., Makarenkova N.N., Zaytseva V.L., Philippov D.A. 2018. Influence of flow velocity, river size, a dam, and an urbanized area on biodiversity of lowland rivers. Biosystems Diversity, 26 (4): 292-302. DOI: 10.15421/011844.

29. Klimenko E.N. 2012. Structural and functional aspects of the Nuphar lutea (L.) Smith heterphylly: ultrastructure and photosynthesis. Cytology and Genetics, 46 (5): 272-279. DOI: $10.3103 /$ S0095452712050052.

30. Kordyum E., Klimenko E. 2013. Chloroplast ultrastructure and chlorophyll performance in the leaves of heterophyllous Nuphar lutea (L.) Smith. plants. Aquatic Botany, 110: 84-91. DOI: 10.1016/j.aquabot.2013.05.013.

31. Krylova E.G. 2010. Structure of hydrophilic vegetation of a small river in an urban environment. Inland Water Biology, 3 (2): 119-125. DOI: 10.1134/S1995082910020033. 
32. Kurashov E.A., Mitrukova G.G., Krylova J.V., Chernova A.M. 2014. Low-molecular-weight metabolites of aquatic macrophytes growing on the territory of Russia and their role in hydroecosystems. Contemporary Problems of Ecology, 7 (4): 433-448. DOI: 10.1134/S1995425514040064.

33. Marrottea R.R., Chmuraa G.L., Stoneb P.A. 2012. The utility of Nymphaeaceae sclereids in paleoenvironmental research. Review of Palaeobotany and Palynology, 169 (1): 29-37. DOI: 10.1016/j.revpalbo.2011.10.007.

34. Mazej Z., Germ M. 2009. Trace element accumulation and distribution in four aquatic macrophytes. Chemosphere, 74 (5): 642-647. DOI: 10.1016/j.chemosphere.2008.10.019.

35. Nurminen L., Horppila J. 2009. Life form dependent impacts of macrophyte vegetation on the ratio of resuspended nutrients. Water Research, 43 (13): 3217-3226. DOI: 10.1016/j.watres.2009.04.041.

36. Ozer J., Levi T., Golan-Goldhirsh A., Gopas J. 2015. Anti-inflammatory effect of a Nuphar lutea partially purified leaf extract in murine models of septic shock. Journal of Ethnopharmacology, 161: 86-91. DOI: 10.1016/j.jep.2014.11.048.

37. Yildirim A.B., Karakas F.P., Turker A.U. 2013. In vitro antibacterial and antitumor activities of some medicinal plant exracts, growing in Turkey. Asian Pacific Journal of Tropical Medicine, 6 (8): 616-624. DOI: 10.1016/S1995-7645(13)60106-6.

\section{References}

1. Atlas arealov i resursov lekarstvennykh rasteniy SSSR [Atlas of areas and resources of medicinal plants of the USSR]. 1980. Moscow, Glavnoe upravlenie geodezii i kartografii pri Sovete Ministrov SSSR, $340 \mathrm{p}$.

2. Belenovskaya L.M., Medvedeva L.I. 2008. Sem. 2. Nymphaeaceae Salisb. - Kuvshinkovye [Fam. 2. Nymphaeaceae Salisb. - Water lilies]. In: Rastitel'nye resursy Rossii: Dikorastuschie tsvetkovye rasteniya, ikh komponentnyi sostav i biologicheskaya aktivnost'. T. 1. Semeistva Magnoliaceae Junglandaceae, Ulmaceae, Moraceae, Cannabaceae, Urticaceae [Plant resources of Russia: wild flowering plants, their component composition and biological activity. Vol. 1. Magnoliaceae - Junglandaceae, Ulmaceae, Moraceae, Cannabaceae, Urticaceae]. Saint-Petersburg, Moscow, KMK Press: 18-20.

3. Bobrov Yu.A. 2017. Growth forms of aquatic herbs in the northeast of European Russia. Arctic Environmental Research, 17 (2): 104-112. DOI: 10.17238/issn2541-8416.2017.17.2.104. (in Russian)

4. Voronin L.V., Tschernyakovskaya T.F. Microorganisms complexes successions in decaing leaves of Nuphar lutea in the small river Latka. Yaroslavl Pedagogical Bulletin, 3 (1): 87-91. (in Russian)

5. Gammerman A.F., Grom I.I. 1976. Dikorastuschie lekarstvennye rasteniya SSSR [Wild medicinal plants of the USSR]. Moscow, Meditsina, 288 p.

6. Gidroekologiya ust'evykh oblastei pritokov ravninnogo vodohranilischa [Hydroecology of the estuarine areas of tributaries of the lowland reservoir]. 2015. A.V. Krylov (red.). Yaroslavl, Filigran, 466 p.

7. Goncharova T.A. 1998. Entsiklopediya lekarstvennykh rasteniy. Lecheniye travami. T. 1 [Encyclopedia of medicinal plants. Herbal treatment. Vol. 1]. Moscow, Publishing House MSP, 560 p.

8. Ivicheva K.N., Philippov D.A. 2017. Aquatic macroinvertebrates of raised bogs in the central part of the Vologda Region, Russia. Trudy Karel'skogo Nauchnogo Tsentra Rossijskoj Akademii Nauk, (9): 30-45. DOI: 10.17076/eco472. (in Russian)

9. Kuznetsova M.A. 1987. Lekarstvennoe rastitel'noe syr'yo i preparaty [Medicinal plant materials and preparations]. Moscow, Vysshaya shkola, $190 \mathrm{p}$.

10. Kurashov E.A., Krylova U.V., Chernova A.M., Mitrukova G.G. 2013. Component composition of low-molecular volatile organic compounds of Nuphar lutea (Nymphaeaceae) at the beginning of vegetation. Water: chemistry and ecology, (5): 67-80. (in Russian)

11. Lisitsyna L.I., Papchenkov V.G., Artemenko V.I. 2009. Flora vodoyomov volzhskogo bassejna. Opredelitel' sosudistykh rastenij [Flora of water bodies of the Volga river basin. Identification guide of vascular plants]. Moscow, KMK Press, $219 \mathrm{p}$.

12. Lobunicheva E.V., Borisov M.Ya., Filonenko I.V., Philippov D.A. 2013. Otsenka ekologicheskogo sostoyaniya malykh vodoyomov [Environmental assessment of small water bodies]. Vologda, GosNIORH, 218 p.

13. Makhlayuk V.P. 1992. Lekarstvennye rasteniya v narodnoy meditsine [Medicinal plants in folk medicine]. Moscow, Niva Rossii, $477 \mathrm{p}$.

14. Sinkyavichene Z.V. 1992. Kharakteristika rastitel'nosti srednikh i malykh rek Litvy [Characteristics of the vegetation of small and medium-sized rivers of Lithuania]. Abstract. dis. ... cand. biol. sciences. Vilnius, 28 p. 
15. Tzvelev N.N. 2000. Opredelitel' sosudistykh rastenij Severo-Zapadnoj Rossii (Leningradskaya, Pskovskaya i Novgorodskaya oblasti) [Manual of the vascular plants of North-West Russia (Leningrad, Pskov and Novgorod provinces)]. Saint-Petersburg, Saint-Petersburg State ChemicalPharmaceutical Academy Press, 781 p.

16. Chernova A.M. 2013. Sezonnaya dinamika produktivnosti kubyshki zhyoltoy (Nuphar lutea, Nymphaeaceae) v usloviyakh malykh rek Verkhnego Povolzh'ya [Seasonal dynamics of productivity of the yellow water lilly (Nuphar lutea, Nymphaeaceae) in the conditions of small rivers of the Upper Volga]. Abstract. dis. ... cand. biol. sciences. Borok, 21 p.

17. Chernova A.M. 2014. The relation of rhizome mass to the morphometric parameters in the Nuphar lutea rhizomes (Nymphaeaceae). Rastitelnye resursy, 50 (1): 17-24. (in Russian)

18. Sharapov A.V., Chemeris E.V., Bobrov A.A. 2013. Resources of standing phytomass of river macrophytes in the Upper Volga region and its seasonal dynamics. Rastitelnye resursy, 49 (1): 48-56. (in Russian)

19. Sheichenko V.I., Tolkachev O.N., Osipov V.I., Sheichenko O.P., Anufrieva V.V., Timoshina V.A., Fateeva T.V., Bortnikova V.V., Bykov V.A. Composition and biological activity of Furanoquinolyzidine Alkaloids from yellow water-lily (Nuphar lutea L. Smith) rhizomes. KhimikoFarmatsevticheskii Zhurnal, 53 (6): 42-47. DOI: 10.30906/0023-1134-2019-53-6-42-47. (in Russian)

20. Chernova A.M. 2015. Seasonal dynamics of yellow water lily Nuphar lutea (L.) Smith (Nymphaeaceae) in the small Ild river (Yaroslavl Oblast). Inland Water Biology, 8 (2): 157-165. DOI: $10.1134 /$ S1995082915020042.

21. Chernova A.M. 2019. Non-destructive estimation of the leaf area in Nuphar lutea L. (Nymphaeaceae). Phytomorphology, 13: 20-25. DOI: 10.5281/zenodo.190105.

22. Czeczuga B., Czeczuga-Semeniuk E., Semeniuk-Grell A., Godlewska A., Muszyńska E. 2018. Influence of different parts of yellow and white water lilies (Nymphaeaceae) on aquatic mycotal species diversity. Nova Hedwigia, 107 (3-4): 367-384. DOI: 10.1127/nova_hedwigia/2018/0483.

23. Didukh M.Ya., Didukh G.Ya., Mazur T.P., Nuzhyna N.V. 2017. Biomorphological and anatomic researches of Nymphaea alba, Nuphar lutea and Nuphar pumila in outdoor and indoor ponds in the A.V. Fomin botanical garden. Hydrobiological Journal, 53 (3): 52-59. DOI: 10.1615/HydrobJ.v53.i3.50.

24. El-On J., Ozer J., Gopas J., Sneir R., Golan-Goldhirsh A. 2009. Nuphar lutea: In vitro antileishmanial activity against Leishmania major promastigotes and amastigotes. Phytomedicine, 16 (8): 788-792. DOI: 10.1016/j.phymed.2009.01.011.

25. Elakovich S.D., Yang J. 1996. Structures and allelopathic effects of Nuphar alkaloids: Nupharolutine and 6,6'-dihydroxythiobinupharidine. Journal of Chemical Ecology, 22 (12): 2209-2219. DOI: 10.1007/BF02029541.

26. Fedotcheva T.A., Shimanovskii N.L., Sheichenko O.P., Anufrieva V.V., Sheichenko V.I., Fedotcheva N.I. 2017. Preparation of Nuflein - an alkaloid from the yellow waterlilly Nuphar lutea - and its cytotoxic action on cultures of normal and tumorous human cells. Pharmaceutical Chemistry Journal, 51 (7): 590-595. DOI: 10.1007/s11094-017-1658-4.

27. Ivanova A.A., Philippov D.A., Kulichevskaya I.S., Dedysh S.N. 2018. Distinct diversity patterns of Planctomycetes associated with the freshwater macrophyte Nuphar lutea (L.) Smith. Antonie van Leeuwenhoek, 111 (6): 811-823. DOI: 10.1007/s10482-017-0986-4.

28. Ivicheva K.N., Makarenkova N.N., Zaytseva V.L., Philippov D.A. 2018. Influence of flow velocity, river size, a dam, and an urbanized area on biodiversity of lowland rivers. Biosystems Diversity, 26 (4): 292-302. DOI: 10.15421/011844.

29. Klimenko E.N. 2012. Structural and functional aspects of the Nuphar lutea (L.) Smith heterphylly: ultrastructure and photosynthesis. Cytology and Genetics, 46 (5): 272-279. DOI: $10.3103 /$ S0095452712050052.

30. Kordyum E., Klimenko E. 2013. Chloroplast ultrastructure and chlorophyll performance in the leaves of heterophyllous Nuphar lutea (L.) Smith. plants. Aquatic Botany, 110: 84-91. DOI: $10.1016 /$ j.aquabot.2013.05.013.

31. Krylova E.G. 2010. Structure of hydrophilic vegetation of a small river in an urban environment. Inland Water Biology, 3 (2): 119-125. DOI: 10.1134/S1995082910020033.

32. Kurashov E.A., Mitrukova G.G., Krylova J.V., Chernova A.M. 2014. Low-molecular-weight metabolites of aquatic macrophytes growing on the territory of Russia and their role in hydroecosystems. Contemporary Problems of Ecology, 7 (4): 433-448. DOI: 10.1134/S1995425514040064. 
33. Marrottea R.R., Chmuraa G.L., Stoneb P.A. 2012. The utility of Nymphaeaceae sclereids in paleoenvironmental research. Review of Palaeobotany and Palynology, 169 (1): 29-37. DOI: 10.1016/j.revpalbo.2011.10.007.

34. Mazej Z., Germ M. 2009. Trace element accumulation and distribution in four aquatic macrophytes. Chemosphere, 74 (5): 642-647. DOI: 10.1016/j.chemosphere.2008.10.019.

35. Nurminen L., Horppila J. 2009. Life form dependent impacts of macrophyte vegetation on the ratio of resuspended nutrients. Water Research, 43 (13): 3217-3226. DOI: 10.1016/j.watres.2009.04.041.

36. Ozer J., Levi T., Golan-Goldhirsh A., Gopas J. 2015. Anti-inflammatory effect of a Nuphar lutea partially purified leaf extract in murine models of septic shock. Journal of Ethnopharmacology, 161: 86-91. DOI: 10.1016/j.jep.2014.11.048.

37. Yildirim A.B., Karakas F.P., Turker A.U. 2013. In vitro antibacterial and antitumor activities of some medicinal plant exracts, growing in Turkey. Asian Pacific Journal of Tropical Medicine, 6 (8) :616-624. DOI: 10.1016/S1995-7645(13)60106-6.

Поступила в редакичю 29.10.2019 г.

\section{Ссылка для цитирования статьи}

For citation

Чернова А.М., Филиппов Д.А. 2019. Запасы сырья Nuphar lutea (L.) Sm. в верховье малой реки Ильд (Ярославская область). Полевой журнал биолога. 1(4):209-217. DOI: 10.18413/2658-3453-2019-1-4-209-217

Chernova A.M., Philippov D.A. 2019. Stocks of Nuphar lutea (L.) Sm. in Small River Ild (Yaroslavl Region, Russia). Field Biologist Journal. 1(4):209-217. DOI: 10.18413/2658-3453-2019-1-4-209-217 